Article

\title{
Dynamics of Confined Short-Chain alkanol in MCM-41 by Dielectric Spectroscopy: Effects of matrix and system Treatments and Filling Factor
}

\author{
Josef Bartoš ${ }^{1, *}$, Silvia Arrese-Igor ${ }^{2} \oplus$, Helena Švajdlenková ${ }^{1}$, Angela Kleinová ${ }^{1}$ and \\ Angel Alegría 2,3 (D) \\ 1 Polymer Institute of SAS, Dúbravská cesta, 984541 Bratislava, Slovakia; \\ Helena.Svajdlenkova@savba.sk (H.Š.); Angela.Kleinova@savba.sk (A.K.) \\ 2 Centro de Física de Materiales, CSIC-UPV/EHU, Paseo Manuel de Lardizabal 5, 20018 San Sebastián, Spain; \\ Silvia.Arreseigor@Ehu.Eus (S.A.-I.); Angel.Alegria@ehu.eus (A.A.) \\ 3 Departamento de Física de Materiales, UPV/EHU, Apartado 1072, 20080 San Sebastián, Spain \\ * Correspondence: Jozef.Bartos@savba.sk; Tel.: +00421-2-3229-4324
}

Received: 20 December 2019; Accepted: 2 March 2020; Published: 7 March 2020

\begin{abstract}
The dynamics of n-propanol confined in regular MCM-41 matrix with the pore size $D_{\text {pore }}=$ $40 \AA$, under various matrix conditioning and sample confining conditions, using broadband dielectric spectroscopy (BDS), is reported. First, various drying procedures with the capacitor filling under air or $\mathrm{N}_{2}$ influence the BDS spectra of the empty MCM-41 and the confined $n-\mathrm{PrOH} / \mathrm{MCM}-41$ systems, but have a little effect on the maximum relaxation time of the main process. Finally, various filling factors of $n-\mathrm{PrOH}$ medium in the optimally treated MCM-41 system lead to unimodal or bimodal spectra interpreted in terms of the two distinct dynamic phases in the confined states.
\end{abstract}

Keywords: short-chain alkanol; MCM-41 matrix; relaxation dynamics; BDS; humidity; FT M-IR

\section{Introduction}

The topic of bulk vs. confined organic materials is usually studied by a variety of classic experimental techniques. Changes in dynamics of various organic media as reflected by specific intrinsic probes of material, such as dynamic density fluctuations, reorientations of magnetic and electric dipoles are detected by means of neutron scattering (NS), nuclear magnetic resonance (NMR) or dielectric relaxation spectroscopy (BDS), respectively, are often observed (see general and special reviews [1-9]). These are related to phase transitions and eventually, to a formation of new phase(s) induced in confined organic medium (filler) by spatial restriction or/and by wall surface of confining inorganic matrix (confiner) [1-4] with their complex impacts into dynamic properties [5-9]. The overall confinement effect, as seen by these standard dynamic techniques, is considered to be a result of the complex mutual interplay of the following two main factors: (i) restricting geometric effects of the pores in a given matrix on the investigated medium and (ii) the mutual interaction effects of the medium's entities with the pore surface wall of the matrix [1-9].

The bulk vs. confinement topic as the multiparameter problem includes a complex mutual action of many internal and external parameters. The most studied group of internal parameters concerns the confining matrix, such as pore size, pore size distribution, pore topology (mutual pore separation or interconnectivity) and pore surface composition and the confined organic medium, such as its size, shape and polarity, and proticity of the molecules. The group of external parameters includes those related to the matrix and confined system conditioning and preparation, such as thermal/time treatments of inorganic matrix in certain atmosphere, filling procedure of confined systems, again under a certain 
atmosphere, as well as degree of filling the pores (filling factor), of the previous specifically treated matrix with a given medium. One of the most often used model inorganic matrices based on silica such as irregular mesoporous silica gels (SG) and regular periodic mesoporous silicas (PMS), e.g., MCM-41 [10-12] and $S B A-15[13,14]$, has the hydrophilic character due to the presence of three basic kinds of polar silanol groups: isolated (free) silanol $[\mathrm{O} \equiv \mathrm{Si}-\mathrm{OH}]$, geminal silanol or silanediol $\left[\mathrm{O}=\mathrm{Si}=(\mathrm{OH})_{2}\right]$ and vicinal silanol $[\mathrm{O} \equiv \mathrm{Si}-\mathrm{OH} . . . \mathrm{HO}-\mathrm{Si} \equiv \mathrm{O}]$, with their different adsorption ability to the environmental moisture $\left(\mathrm{H}_{2} \mathrm{O}\right.$ from air) or other agents [15-18] and the capability of having various modification treatments [17,18]. Consequently, many BDS works addressed this important water-adsorption phenomenon in various silicas [19-22]. However, in spite of the importance of these external parameters, a relatively small amount of attention was devoted to systematic studies of their variations from the viewpoint of their impact into the dynamic response of the various confined organics $[23,24]$. This is also evident from the frequent absence of detailed descriptions of the empty matrix and confined system conditioning, as well as of the filling conditions during the preparation of the confined systems.

The knowledge situation is further complicated for the special group of $H$-bonded compounds, a very important class of organic media. Although the simpler poly alcohols, such as 1,2-ethanediol, ethylene glycol $(E G), 1,2-$ propanediol, propylene glycol $(P G)$ and 1,2,3-propanetriol, glycerol $(G L)$ were among the first model organic media investigated after insertion into various inorganic silica matrices by BDS [25-30], BDS works on confined monohydroxy alcohols are rather limited [24,31-33]. This family of alcohols exhibits basically two peak features, where the main peak consists of two strongly superimposed subpeaks from the dominating Debye relaxation and the essentially less intense primary $\alpha$ one together with the well-separated secondary $\beta$ process [34]. First, branched longer monohydroxy alkanols were studied where well-separated Debye- and $\alpha$-processes were observed [31,32]. Later the first simplest members of the $n$-alkanol family, i.e., methanol and ethanol, were measured under confinement in MCM-41, showing a single global main peak, without any resolution of possible individual processes [24,33].

$\mathrm{N}$-propanol, $\mathrm{CH}_{3} \mathrm{CH}_{2} \mathrm{CH}_{2} \mathrm{OH}$, (n-PrOH) is a typical amphiphilic organic substance containing both the apolar alkyl group and the polar hydroxyl one in the molecule, with its ability to form intermolecular $H$-bonded associates (aggregates) in the liquid state [34]. Basic structural and dynamic properties of $n-\mathrm{PrOH}$ in the bulk state were investigated by classic structural $\mathrm{X}$-ray and neutron diffraction (XD and ND) techniques, together with various Monte Carlo and molecular dynamics (MC and MD) simulations, as well as Empirical Potential Structure Refinement (EPSR) modeling [35-38], and by dynamics techniques, such as BDS and neutron scattering (NS) [39-41], so that the structural-dynamic state of the bulk liquid $n-\mathrm{PrOH}$ is quite well understood. On the other hand, a few works only were focused on dynamic behavior of small alkanols, such as $n-\mathrm{PrOH}$ confined in various microscopic porous inorganic matrices [42]. In addition, recently, some of us performed electron spin resonance (ESR) studies via spin probe method on the bulk $n-\mathrm{PrOH}$ [43] and on the respective saturated confined states in the irregular virgin silica gels (SGs) [44], as well as in the regular virgin MCM-41 [45], showing significant differences in the spin probe 2,2,6,6-tetramethyl-piperidinyl-1-oxy (TEMPO) dynamics, as well as in its dynamic heterogeneity with respect to the bulk $n-\mathrm{PrOH}$ medium.

In this contribution, we present the results of detailed systematic BDS studies of the relaxation dynamics of $n-P r O H$ embedded in a periodic silica-based matrix. The MCM-41 type silica matrix with the defined pore size, pore topology and pore composition [10-12] was investigated in detail by a variation of external variables, such as (i) thermal, i.e., temperature/time treatment and capacitor filling of the empty MCM-41 matrix under various atmospheres, i.e., air and nitrogen; (ii) pore and capacitor filling of the $n-\mathrm{PrOH} / \mathrm{MCM}-41$ systems under various atmospheres; and (iii) different filling factor of the confined medium/matrix system for the most optimally treated empty MCM-41 matrix, as well as the most optimally prepared confined $n-\mathrm{PrOH} / \mathrm{MCM}-41$ system.

\section{Materials and Methods}

Anhydrous n-Propanol ( $n$-PrOH) from Sigma-Aldrich, Inc., Germany, with a purity of $99.7 \%$ was used as confined organic medium (filler). Regular virgin Mobil Composition of Matter (MCM-41) silica 
matrix having regularly (parallelly) ordered cylinder-like channels with the mean pore size $D_{\text {pore }}=40$ $\AA$, from Sigma-Aldrich, Inc., Germany, was utilized as a confining inorganic material.

\subsection{FTIR Measurements}

First, the conditioning by drying procedure of the empty MCM-41 was monitored by Fourier transform middle-infrared (FT M-IR) spectroscopy. The empty MCM-41 matrix was undergone to stepwise drying for $0,1,3,6$ and 7 days, in the vacuum oven (VO), and subsequently immediately measured in FTIR spectrometer Nicolet $8700^{\mathrm{TM}}$, Thermo Scientific, Madison, WI, USA, in transmission mode, under the standard air atmosphere. The analyzed samples in amounts below $2 \mathrm{mg}$ were grounded in the ball mill, along with calcium bromide. Then the ground powder was molded into pellets. The corresponding spectra were taken throughout the whole middle infrared region (4000-400 $\mathrm{cm}^{-1}$ ) and normalized by converting to unit mass. The calcium bromide (KBr, CAS: 7758-02-3) used was a FTIR-grade product purchased from Sigma-Aldrich Chemie, Steinheim, Germany. The $\mathrm{KBr}$ was dried at $120^{\circ} \mathrm{C}$, in a common oven, in air atmosphere, before measurement. The resolution of spectra was set to $4 \mathrm{~cm}^{-1}$, and the number of scans was 32 in every case.

Next, the empty MCM-41 matrix was exposed to various conditioning treatments that consisted of three different drying procedures before BDS measurements. These sample preparations of $M C M-41$ matrix included the following: (i) drying at specific drying temperature of $120{ }^{\circ} \mathrm{C}$, in the $\mathrm{VO}$, for different drying times, $0,1,3,6$ and 7 days, followed by filling the capacitor under air $\left(\mathrm{O}_{2}+\mathrm{N}_{2}+\right.$ moisture $)$ atmosphere; (ii) drying at $120^{\circ} \mathrm{C}$ for 1 day, in the $\mathrm{VO}$, followed by filling the capacitor under inert nitrogen atmosphere in the glove box (GB); and finally (iii) drying at $120^{\circ} \mathrm{C}$ directly in the BDS cell, under $N_{2}$ atmosphere, for different drying times, $1-8 \mathrm{~h}$ with subsequent immediate BDS measurements at $150 \mathrm{~K}$.

\subsection{BDS Measurements}

The confined $n-\mathrm{PrOH} / \mathrm{MCM}-41$ systems for BDS studies were prepared by adding $n$ - $\mathrm{PrOH}$ into the MCM-41 powder, drop by drop, and stirring till the desired weight ratio was achieved (see Table 1). For the underfilled and saturated cases, capillary forces were allowed to fill the accessible pores of matrices with $n-\mathrm{PrOH}$ so that no liquid remained on the external surface of the silica grains. By further adding the $n-\mathrm{PrOH}$ medium, the overfilled state with the $n-\mathrm{PrOH}$ molecules in the inter-grain silica space was achieved. Two different environments were tested for capacitor preparation and for the $n-\mathrm{PrOH}$ filling of MCM-41 matrix: under regular air (mixture of $\mathrm{N}_{2}+\mathrm{O}_{2}+$ moisture $\left(\mathrm{H}_{2} \mathrm{O}\right)$ in laboratory and under inert $N_{2}$ atmosphere in the GB. The theoretical and real mass fractions of the filler for each filler/confiner system, as well as the ratios of the latter quantity to the former one, are listed in Table 1.

Table 1. Matrix and confined n-PrOH/MCM-41 systems.

\begin{tabular}{|c|c|c|c|c|c|c|}
\hline Matrix & $\begin{array}{c}\text { Pore Diameter } \\
D_{\text {pore, }} \AA\end{array}$ & $\begin{array}{l}\text { Pore Volume } \\
V_{\text {pore }}, \mathrm{cm}^{3} / \mathrm{g}\end{array}$ & $\begin{array}{l}\text { Pore Area } \\
S_{\text {pore }}, \mathrm{m}^{2} / \mathrm{g}\end{array}$ & $F_{\mathrm{n}-\mathrm{PrOH}, \text { theo }} *$ & $F_{\mathrm{n}-\mathrm{PrOH}, \text { real }} * *$ & $X * * * \%$ \\
\hline $\begin{array}{l}M C M-41 \\
\text { underfilled }\end{array}$ & 40 & 0.80 & 1098 & 0.39 & 0.235 & 60.3 \\
\hline $\begin{array}{l}M C M-41 \\
\text { saturated }\end{array}$ & 40 & 0.80 & 1098 & 0.39 & 0.359 & 92.1 \\
\hline $\begin{array}{l}\text { MCM-41 } \\
\text { overfilled }\end{array}$ & 40 & 0.80 & 1098 & 0.39 & 0.456 & 116.9 \\
\hline
\end{tabular}

${ }^{*} F_{\mathrm{n}-\mathrm{PrOH} \text {,theo }}=m_{\mathrm{n}-\mathrm{PrOH}} /\left(m_{\mathrm{n}-\mathrm{PrOH}}+m_{\mathrm{MCM}-41}\right)$, the theoretical mass fraction of $n$-PrOH medium with respect to the $n-\mathrm{PrOH} / \mathrm{MCM}-41$ system estimated using the density of $n-\mathrm{PrOH}$ at room temperature, $\rho_{\mathrm{n} \text {-PrOH }}(\mathrm{RT})=0.803$ $\mathrm{g} / \mathrm{cm}^{3}$ under the complete accessibility condition of all the regular pores for the $n-\mathrm{PrOH}$ medium, ${ }^{* *} F_{\mathrm{n}-\mathrm{PrOH} \text {,sat }}$ $=m_{\mathrm{n}-\mathrm{PrOH}} /\left(m_{\mathrm{n}-\mathrm{PrOH}}+m_{\mathrm{MCM}-41}\right)$, the real experimental mass fraction of $n-\mathrm{PrOH}$ in the $n-\mathrm{PrOH} / \mathrm{MCM}-41$ system corresponding to the three different filling situations of the $n-\mathrm{PrOH}$ in the $n-\mathrm{PrOH} / \mathrm{MCM}-41$ system, ${ }^{* * *} \mathrm{X}=$ $\left(F_{\mathrm{n}-\mathrm{PrOH} \text {,sat }} / F_{\mathrm{n}-\mathrm{PrOH} \text {,theo }}\right) \times 100 \%$.

BDS measurements were performed by using a high-resolution Novocontrol dielectric analyzer in the range $10^{-1}-10^{7} \mathrm{~Hz}$. Isothermal frequency scans were performed over the temperature interval from 
100 to $300 \mathrm{~K}$, with a temperature step of $5 \mathrm{~K}$. The $M C M-41$ powder and $n-P r O H$ containing $M C M-41$ powder samples and liquid samples were placed between two parallel plate capacitors, without or with a Teflon spacer, with a thickness of $100 \mu \mathrm{m}$, respectively.

\section{Results}

\subsection{Effect of the Conditioning of the Empty MCM-41 Matrix on the M-IR and BDS Response.}

First, we investigated the influence of various thermal treatments on the empty MCM-41 matrix by M-IR and BDS techniques. The treatments consisted of (i) drying the MCM-41 samples at a specific drying temperature, $T_{\mathrm{d}}=393 \mathrm{~K}\left(120^{\circ} \mathrm{C}\right)$, for various drying times, $t_{\mathrm{d}}$, in the VO or directly in the BDS cell; and (ii) subsequent sample preparation of the variously dried MCM-41 matrix into the M-IR cell, under air or into the capacitor of the BDS cell, under various atmospheres, i.e., under regular air or inert nitrogen $\left(N_{2}\right)$ in the GB.

Figure 1 shows the M-IR spectra of the MCM-41 as a function of drying time, $t_{\mathrm{d}}=0,1,3,6$ and 7 days, in the VO, followed by sample preparation of the M-IR cell under air atmosphere. Here, the spectral bands at the wavenumbers of 1630 and $~ 3500 \mathrm{~cm}^{-1}$ are ascribed to the bound $\mathrm{H}_{2} \mathrm{O}$ molecules to the silanol groups of silica $[15,16]$. The presence of even a small amount of water at the surface of the silica matrix may significantly contribute to its dielectric response [19-22]. After drying the empty MCM-41 material in the VO for six days, followed by subsequent sample preparation of the M-IR cell under air atmosphere, the intensity of this particular peak becomes almost constant.

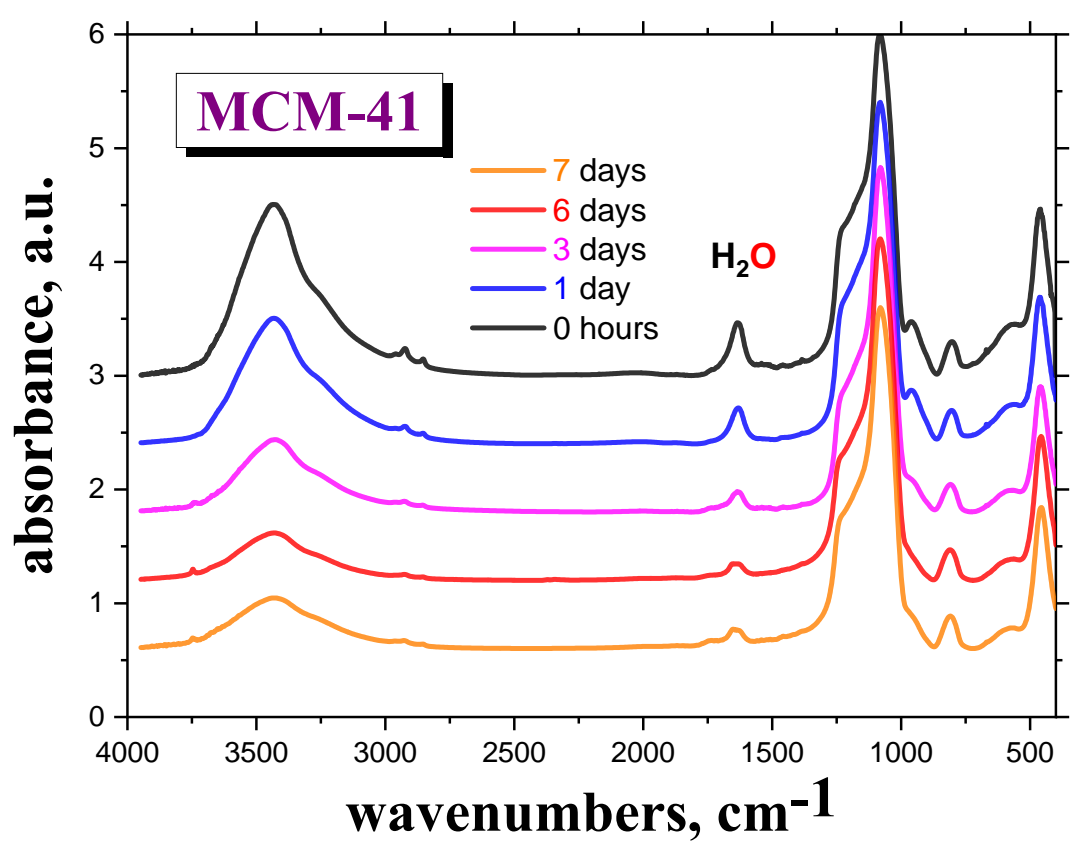

Figure 1. M-IR spectra of the empty $M C M-41$ dried in the VO at specific drying temperature, $T_{\mathrm{d}}=120$ ${ }^{\circ} \mathrm{C}$, for various drying times, $t_{\mathrm{d}}=0,1,3,6$ and 7 days. Filling the M-IR cell was carried out at $R T$, under air atmosphere. The peaks at $\nu \sim 1630$ and $\sim 3500 \mathrm{~cm}^{-1}$ belong to the bonded $\mathrm{H}_{2} \mathrm{O}$ to the silanol groups of MCM-41 matrix [15,16].

Figure 2 shows BDS spectra of the MCM-41 matrix samples under different drying and atmosphere conditions, at some representative temperature, $T=150 \mathrm{~K}$. As it can be seen, the dielectric response of those samples exposed to air for capacitor preparation after six days of drying exhibits a relatively intense loss peak at $\mathrm{f}_{\max }(150 \mathrm{~K}$, air $) \approx 1 \times 10^{4} \mathrm{~Hz}$. In contrast, the $M C M-41$ samples exposed to $N_{2}$ for capacitor preparation after one day drying exhibit almost one order of magnitude lower intensity centered at a relatively lower $\mathrm{f}_{\max }\left(150 \mathrm{~K}, \mathrm{~N}_{2}\right) \approx 3 \mathrm{~Hz}$. These results indicate that the quality of atmosphere in contact with the matrix after drying is more determinant than the drying time on 
decreasing the amount of water molecules of the host matrix. Note that, according to M-IR data, the moisture content after one day of drying is higher than that after the three days' one, when measured under the same air atmosphere conditions. Consistently, among those samples exposed to $N_{2}$ after drying that dried inside the BDS cell under $N_{2}$ flow shows the lowest signal, followed by that measured right after drying and preparing, and finally, that of a sample stored under $N_{2}$ in the GB for five days before measurement (see Figure 2). It is worth noting that the stepwise drying of the MCM-41 silica reaches the stationary state (no appreciable evolution of the signal) after just two cumulative hours at $393 \mathrm{~K}$.

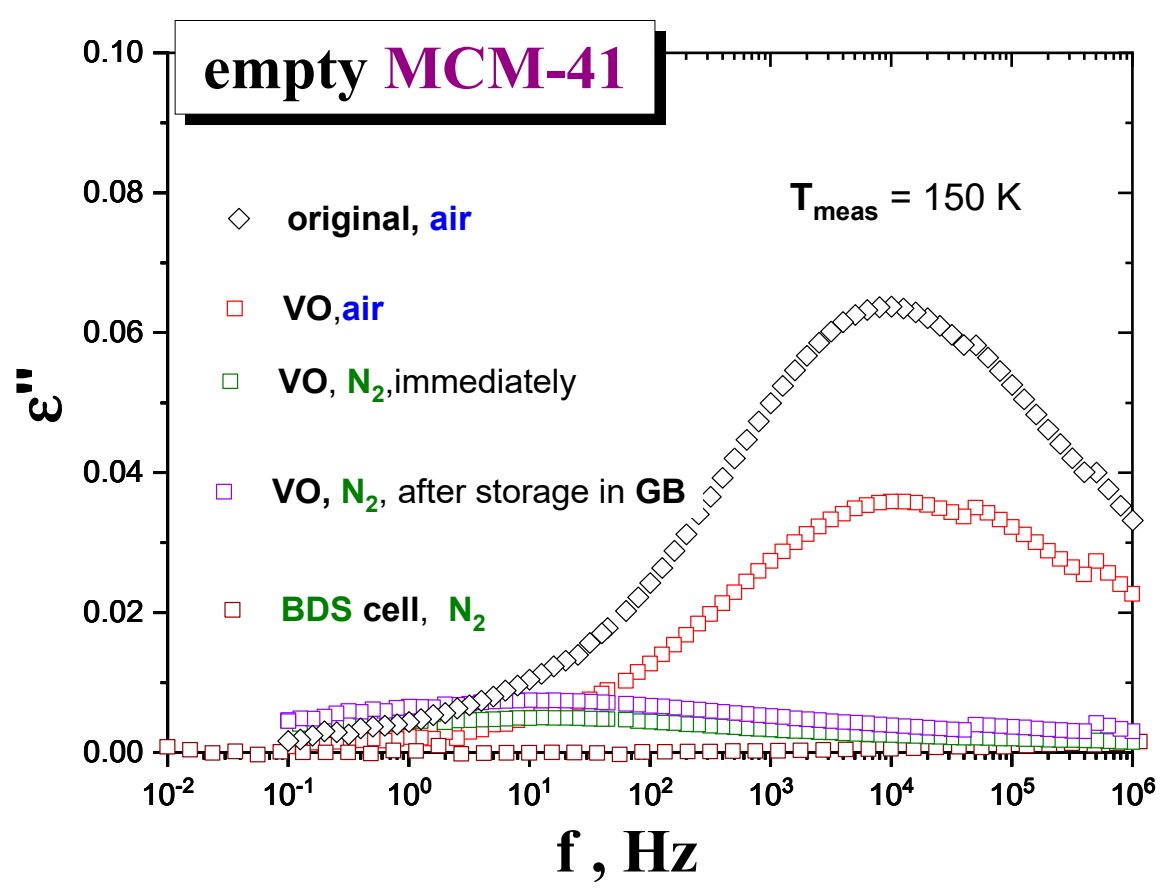

Figure 2. Comparison of the BDS spectra recorded at $150 \mathrm{~K}$ of the empty $M C M-41$ in the original (untreated) state (black diamonds) and in a series of thermally treated empty MCM-41 samples by drying and subsequent manipulation, i.e., loading into the capacitor by various ways: (a) dried in the VO at $120^{\circ} \mathrm{C}$ for six days and subsequently filled into the capacitor under the air $\left(\mathrm{N}_{2}+\mathrm{O}_{2}+\right.$ moisture) atmosphere (red squares); (b) dried in the $\mathrm{VO}$ at $120^{\circ} \mathrm{C}$ for one day and subsequently filled into the capacitor under $N_{2}$ in the GB and measured (i) immediately (green squares) and (ii) after five days' storage in the GB (blue squares) and finally; (c) dried at $120^{\circ} \mathrm{C}$ for $2 \mathrm{~h}$, directly in the BDS cell, under $\mathrm{N}_{2}$ (brown squares). All the empty MCM-41 samples were undergone by the same cooling treatment with $-2 \mathrm{~K} / \mathrm{min}$ from $R T$ down to $100 \mathrm{~K}$ and subsequently measured isothermally with $\Delta T=5 \mathrm{~K}$ from 100 up to $300 \mathrm{~K}$.

These findings emphasize the important effect of matrix thermal treatment, atmosphere exposure and sample preparation conditions on the dielectric response of the empty MCM-41 matrix. Sample preparation details can be critical to understand certain surface effects and should be properly indicated and underlined in the future literature.

\subsection{Effects of Preparation of the Confined n-PrOH/MCM-41 Systems under Various Atmospheres.}

Although the last special drying treatment of MCM-41 matrix directly in the BDS cell is the most effective, it is technically impossible to apply this kind of treatment for own BDS measurements of any filled organic/MCM-41 system because of the inevitable short-term manipulations with the sample under air. Therefore, we have used the standard drying of the MCM-41 matrix in the VO and investigated the effects of both basic types of atmospheres (air and $N_{2}$ ) during preparation of the confined $n-\mathrm{PrOH} / \mathrm{MCM}-41$ systems. Figure 3a-c presents the BDS spectra for the various $n-\mathrm{PrOH} / \mathrm{MCM}-41$ systems 
filled to the three different filling fractions under air or $N_{2}$ atmosphere, respectively. Both spectral data at different atmospheres exhibit some similar and some different features. This is clearly demonstrated in Figures 4 and 5, together with the respective spectral responses from the empty MCM-41 matrices at one selected representative temperature, i.e., $180 \mathrm{~K}$ in both linear and logarithmic representations of dielectric loss.
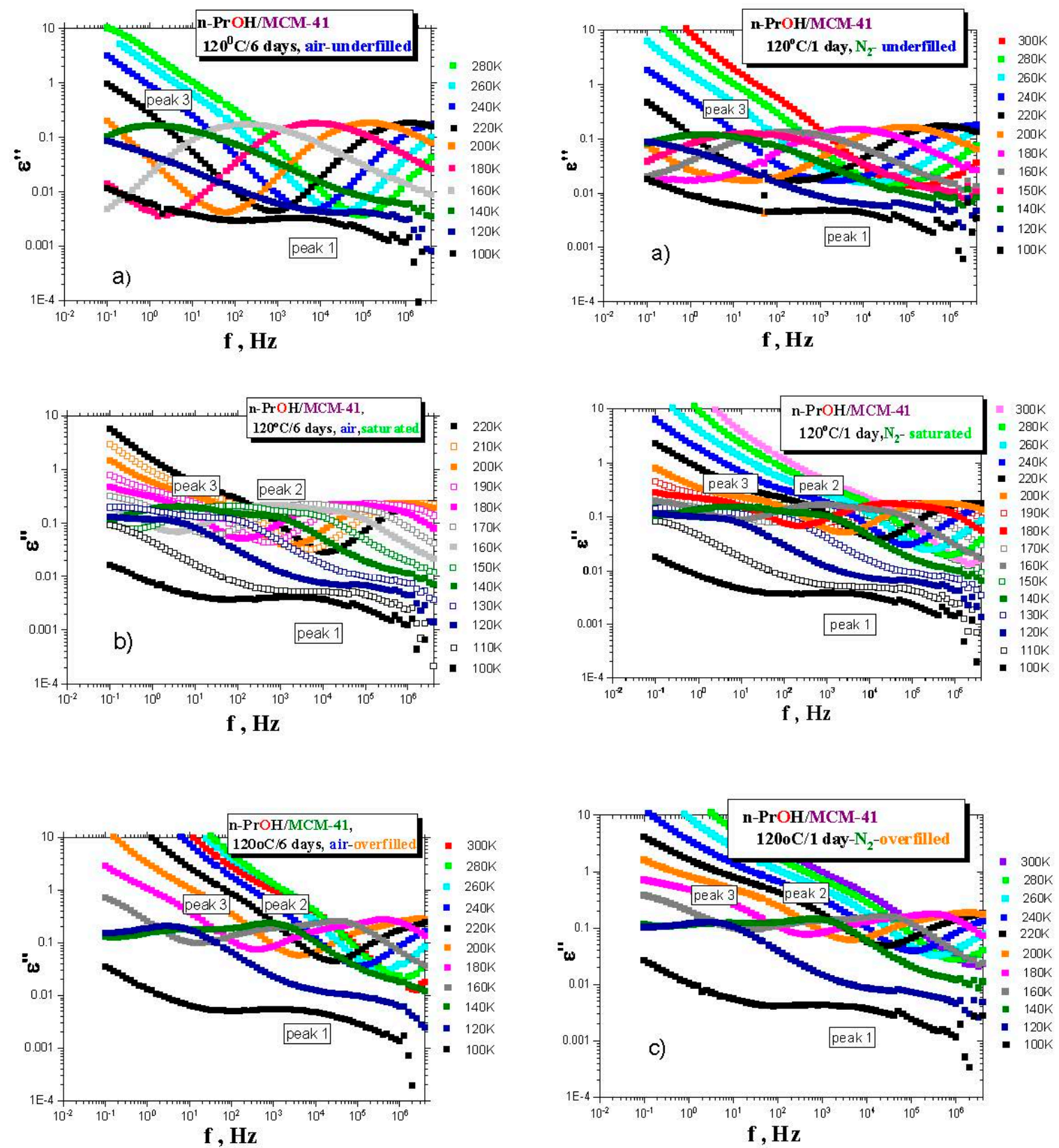

Figure 3. BDS spectral evolutions for the confined $n-P r O H / M C M-41$ underfilled (a), saturated (b) and overfilled (c) systems prepared by drying of the $M C M-41$ at $120^{\circ} \mathrm{C}$ for six days in the $\mathrm{VO}$ and subsequent loading of the $n-\mathrm{PrOH}$ medium into the capacitor under air (left column) and drying of the MCM-41 at $120^{\circ} \mathrm{C}$ for one day in the $\mathrm{VO}$ and subsequent loading of the $n-\mathrm{PrOH}$ medium into the capacitor under $N_{2}$ (right column) The samples were cooled with $-2 \mathrm{~K} / \mathrm{min}$ from $R T$ down to $100 \mathrm{~K}$ and subsequently, isothermally heated with $\Delta T=5 \mathrm{~K}$ from $100 \mathrm{~K}$ up to $280-300 \mathrm{~K}$. 


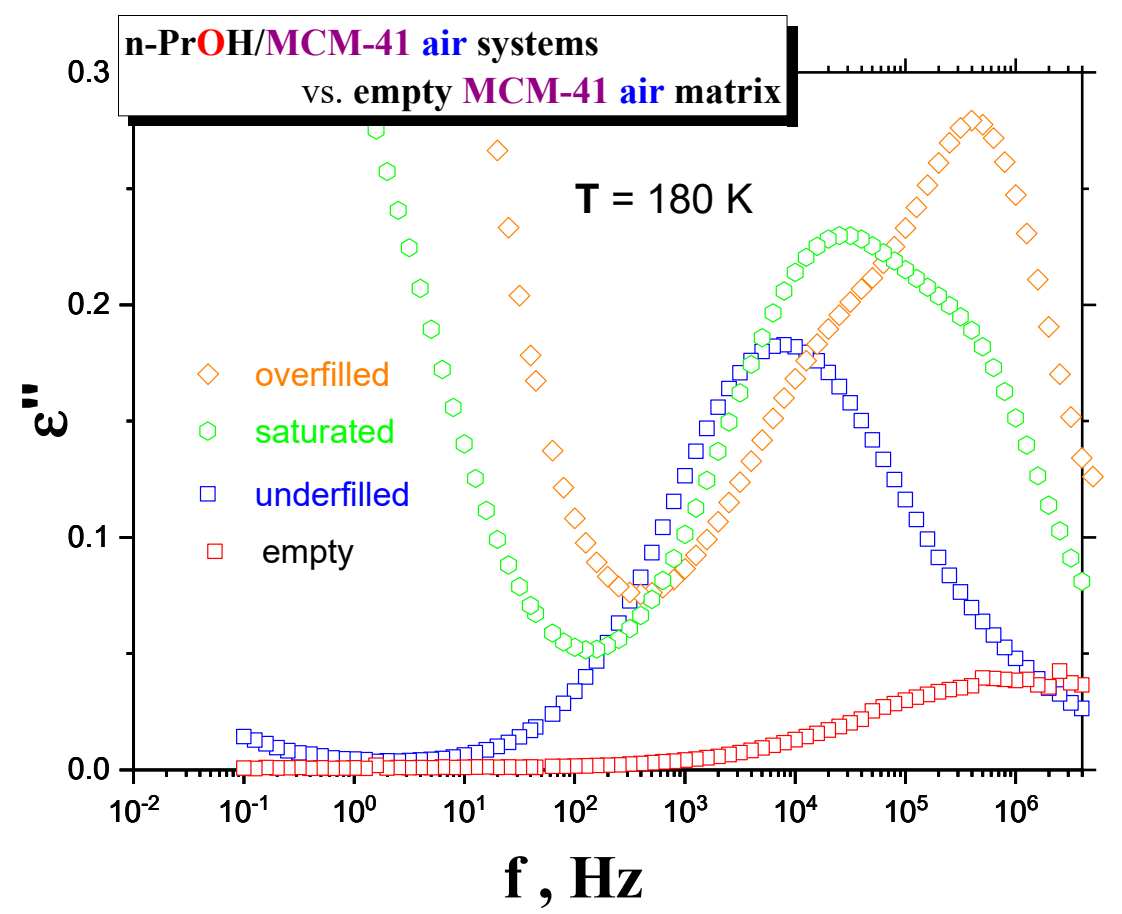

Figure 4. Comparison of the BDS spectra at $180 \mathrm{~K}$ of empty MCM-41 matrix vs. underfilled, saturated and overfilled $n$-PrOH/MCM-41, air systems after cooling with $-2 \mathrm{~K} / \mathrm{min}$ from $R T$ down to $100 \mathrm{~K}$ and subsequently isothermal measured with $\Delta T=5 \mathrm{~K}$ step up to $300 \mathrm{~K}$.

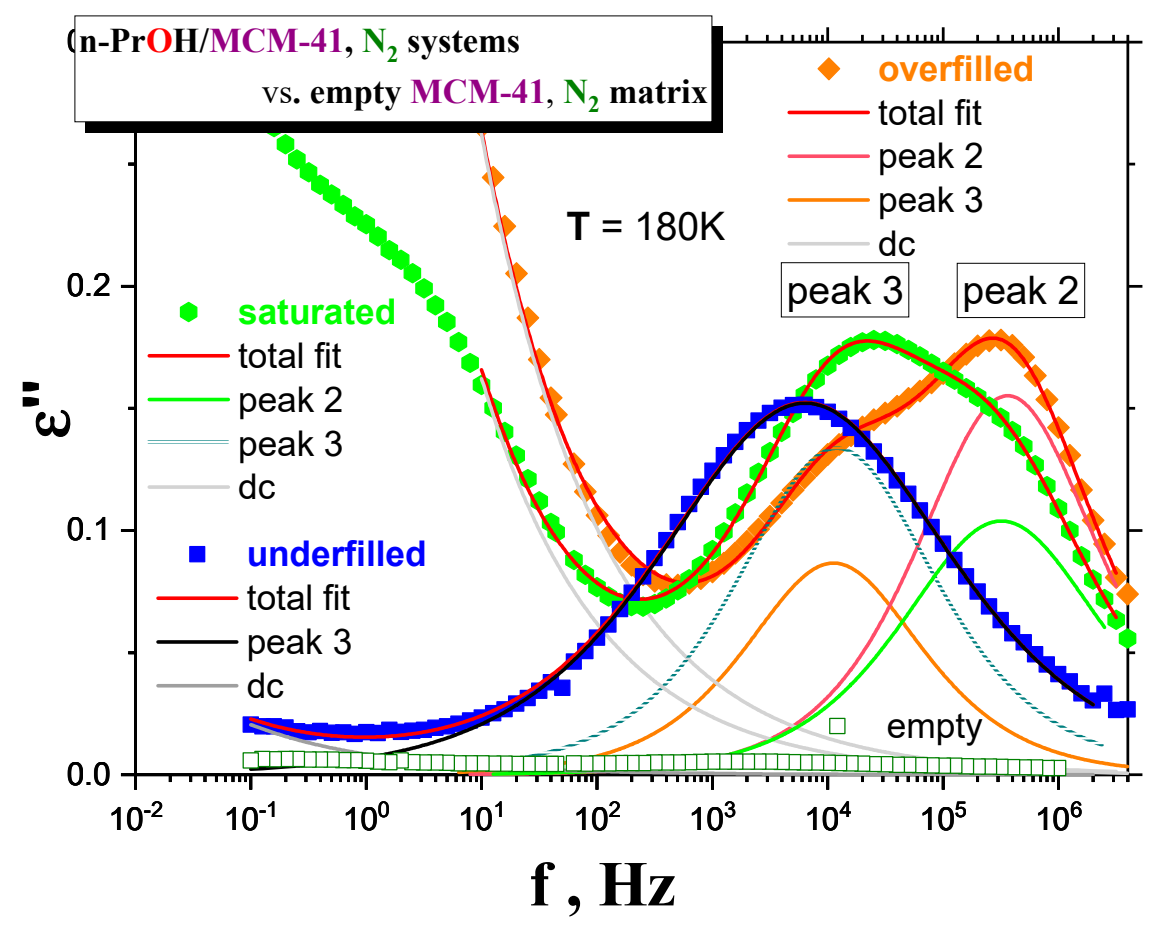

Figure 5. Comparison of the BDS spectra at $180 \mathrm{~K}$ for underfilled, saturated and overfilled $n-\mathrm{PrOH} / \mathrm{MCM}-41, \mathrm{~N}_{2}$ systems, as well as for empty $\mathrm{MCM}-41, \mathrm{~N}_{2}$ and $n-\mathrm{PrOH}$ after cooling with $-2 \mathrm{~K} / \mathrm{min}$ from $R T$ down to $100 \mathrm{~K}$ and subsequently isothermal heated with $\Delta T=5 \mathrm{~K}$ step up to $300 \mathrm{~K}$. Spectral fits using Equation (1) are included.

A similar feature in all of the confined $n-\mathrm{PrOH} / \mathrm{MCM}-41$ systems is the presence of a small and broad peak (peak 1 ) at higher frequencies and lowest temperatures. On the other hand, significant 
differences consist in the character of dielectric spectra for different filling factors, regardless of the used atmosphere. For the overfilled and the saturated $n-\mathrm{PrOH} / \mathrm{MCM}-41$ systems, we observe a bimodal form of the respective spectra with peaks 2 and 3 at higher or lower frequency, respectively. In addition, for both of these types of confined systems differing in their filling fraction, the opposite trend in the peak intensities is evident, i.e., higher intensity of peak 2 with respect to that of peak 3 , in accord with intuitive expectation. Although, in the case of the confined samples exposed to air during sample preparation, peak 2 may contain partial contribution from the losses of the bare MCM-41 matrix-the relative intensities of peaks 1 and 2 are of the same order as those for samples prepared under $\mathrm{N}_{2}$ atmosphere, where the dielectric loss of the MCM- 41 is minimized. On the other hand, the underfilled $n-\mathrm{PrOH} / \mathrm{MCM}-41$ samples exhibit broad unimodal spectra with one spectral feature (peak 3). In general, the characteristic timescales for each of the processes mentioned above are only slightly dependent on the atmosphere under which samples were prepared (pore filling and capacitor preparation).

\subsection{Effects of the Filling Fraction in the Confined n-PrOH/MCM-41, $N_{2}$ Systems under the Most Optimal Atmosphere Conditions.}

From the previous test BDS measurements, it is evident that the most optimal confined $n-\mathrm{PrOH} / \mathrm{MCM}-41$ system treatment consists of drying the empty $M C M-41$ matrix in the $\mathrm{VO}$ at $120{ }^{\circ} \mathrm{C}$ for one day, with the subsequent pore and the capacitor fillings in the GB under $N_{2}$ atmosphere. Figure 6 displays linear representations of the spectral evolution in all the three confined $n-\mathrm{PrOH} / \mathrm{MCM}-41$ differing in the filling fraction. As already mentioned in the previous section, the dramatic qualitative difference between the underfilled $n-\mathrm{PrOH} / \mathrm{MCM}-41$ and the saturated and overfilled n-PrOH/MCM- 41 ones can be found. In contrast to logarithmic representation in Figure 3a,b, which emphases peak 1 at the lowest temperatures and the highest frequencies, linear representations of the LF-BDS spectra demonstrate more pronouncedly this difference in further peak features observed in intermediate temperatures of the BDS window. For the filling fraction 0.24, only one broad peak 3 at relatively lower frequencies exists, and in the latter ones, two peak features, i.e., peaks 3 and 2, are evident. Thus, in the saturated sample, peak 2 is relatively smaller than peak 3 , and it appears over the intermediate temperature range at higher frequencies, while peak 3 is larger and situated at lower frequencies. Finally, for the overfilled system, the frequency positions of peaks 2 and 3 are similar as in the previous fully filled case, but their relative intensities are reversed.

Dielectric spectra for the most optimally treated MCM-41 matrix and the confined n-PrOH/MCM-41 systems were analyzed, using an additive model with the following relaxation function for the imaginary part of the dielectric permittivity $\varepsilon^{\prime \prime}(\omega)$ :

$$
\varepsilon^{\prime \prime}(\omega)=-\operatorname{Im}\left\{\Sigma_{\mathrm{i}} \Delta \varepsilon_{\mathrm{CC}, \mathrm{i}} /\left[1+\left(\mathrm{i} \omega \tau_{\mathrm{CC}, \mathrm{i}}\right)^{\alpha}{ }_{\mathrm{CC}, \mathrm{i}}\right]-\mathrm{i} \sigma / \varepsilon_{0} \omega^{\mathrm{s}}\right\}
$$

The first term on the right-hand side of Equation (1) describes dielectric relaxation due to reorientation of molecules related to peaks $i=1,2$ and 3 . We have adopted the Cole-Cole (CC) function [7] for relaxation function for each component, where $\Delta \varepsilon_{\mathrm{CC}, \mathrm{i}}$ and $\tau_{\mathrm{CC}, \mathrm{i}}$ represent a relaxation strength and characteristic times of ith dielectric relaxation with $\tau_{\max , \mathrm{i}}=\tau_{\mathrm{CC}, \mathrm{i}}$, respectively. The exponent $\alpha(0 \leq \alpha \leq 1)$ is a measure of relaxation time distribution of $\tau_{\mathrm{CC}, \mathrm{i}}$; when $\alpha=1$, the CC function reduces to the Debye (D) function with no distribution of $\tau_{i}$. The last term is an "apparent" conductivity term accounting for dc-conductivity and additional Maxwell-Wagner-Sillar effects (MWS), due to the presence of multiple interphases. 

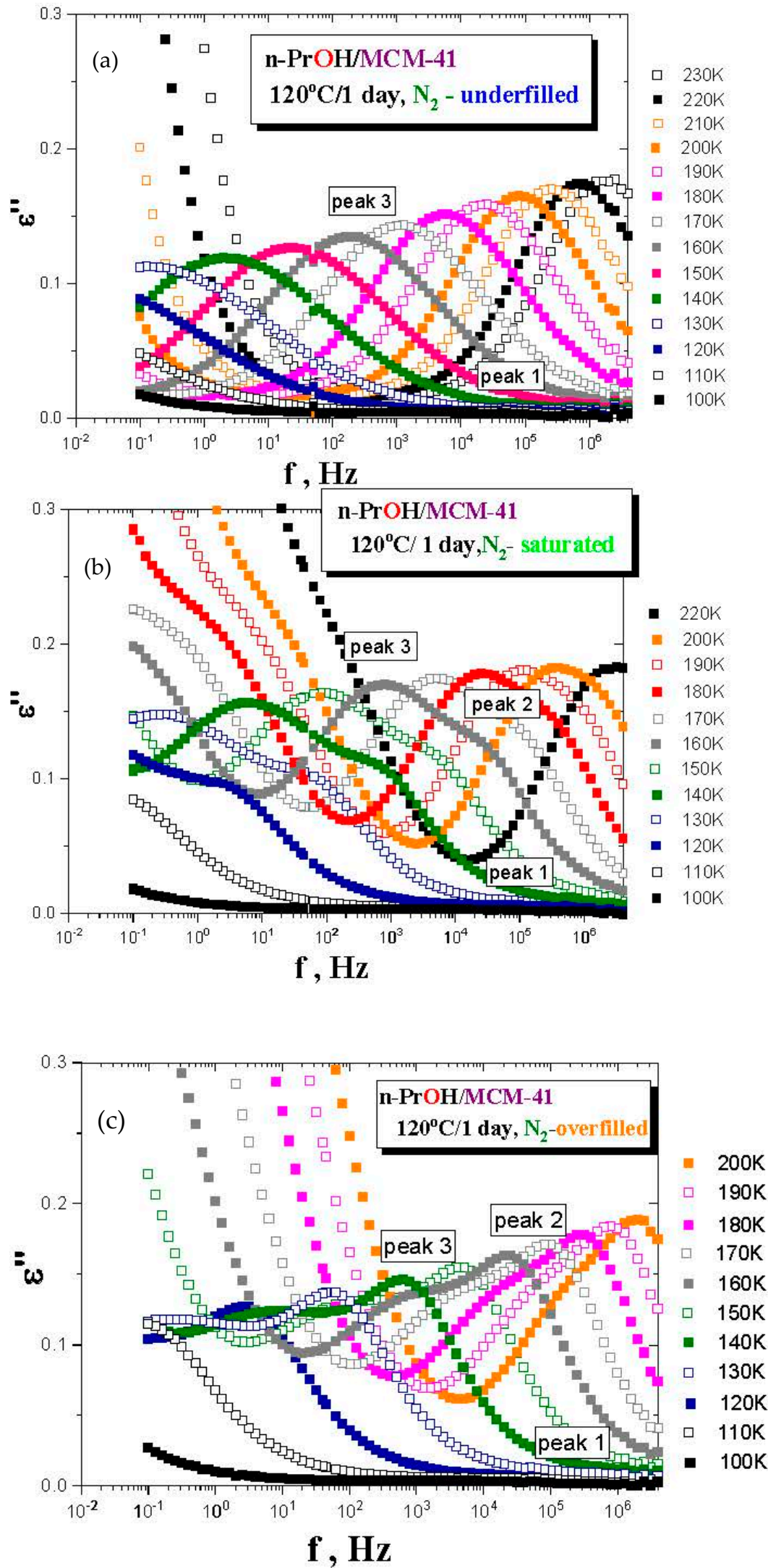

Figure 6. Temperature evolution in the confined $n-\mathrm{PrOH} / \mathrm{MCM}-41, \mathrm{~N}_{2}$ systems: underfilled (a), saturated (b) and overfilled (c), up to 230 and $200 \mathrm{~K}$ for the first two or the last filling factor. 
Figure 7 summarizes the maximum relaxation times, $\tau_{\max }$, for all the three $n-\operatorname{PrOH} / \mathrm{MCM}-41$, $N_{2}$ systems, as obtained from the detailed spectral fitting, using Equation (1), together with the peak maximum of the main peak (the so-called Debye relaxation) of the bulk $n$-PrOH, as determined from the peak maxima. In all the bulk and confined cases, the non-Arrhenius character of the corresponding timescales of one or two main peaks (peaks 3 and 2) over the measured frequency range of the BDS technique is observed with the fitting parameters from the Vogel-Fulcher-Tamman-Hesse (VFTH) equation listed in Table 2. In Table 2, the fitting parameters from the Arrhenius equation for the secondary process (peak 1) in the confined states (data not plotted in Figure 8) are also included together with those for the bulk state from the literature [39-41].

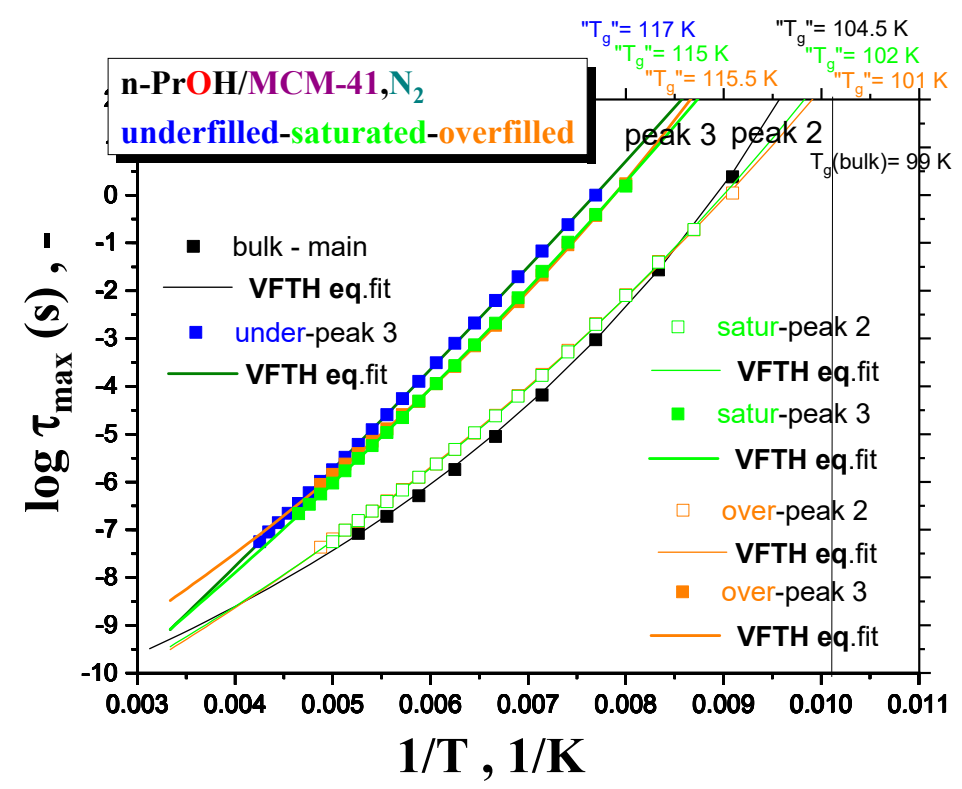

Figure 7. Arrhenius plot of the maximum relaxation times in all the three variously filled $n-\mathrm{PrOH} / \mathrm{MCM}-41, \mathrm{~N}_{2}$ systems, determined from the unimodal spectra for the underfilled $n-\mathrm{PrOH} / \mathrm{MCM}-41, \mathrm{~N}_{2}$ system and from the bimodal ones for the saturated and overfilled $n$-PrOH/MCM-41, $\mathrm{N}_{2}$ ones, together with the corresponding VFTH equation fits with parameters in Table 2.

Table 2. Fitting parameters from the VFTH equation: $\tau_{\max }=\tau_{\infty} \exp \left[B /\left(T-T_{0}\right)\right]$ for the main peak features (peaks 3 and 2) and the Arrhenius equation: $\tau_{\max }=\tau_{\infty} \exp [B / T]$ for the secondary peak one (peak 1) in the bulk n-PrOH and the confined n-PrOH/MCM- $41, N_{2}$ systems.

\begin{tabular}{cccccc}
\hline System & Peak & $\boldsymbol{\Delta T}(\mathbf{K})$ & $\log \boldsymbol{\tau}_{\infty}$ & $\boldsymbol{B}(\mathbf{K})$ & $\boldsymbol{T}_{\mathbf{0}}(\mathbf{K})$ \\
\hline Bulk & 1 & $77-121$ & -14.2 & 1075 & 0 \\
\hline Confined & 2 & $110-190$ & -11.9 & 630.3 & 59 \\
\hline underfilled & 1 & $100-125$ & -16.1 & 1208.1 & 0 \\
\hline & 3 & $130-235$ & -15.4 & 1801.7 & 12.9 \\
\hline saturated & 1 & $100-140$ & -20.1 & 1803.9 & 0 \\
\hline & 2 & $115-200$ & -12.9 & 912.8 & 40.7 \\
\hline overfilled & 1 & $100-140$ & -14.8 & 1094.3 & 0 \\
\hline & 2 & $110-205$ & -13.2 & 982.5 & 36.4 \\
\hline & 3 & $125-205$ & -12.6 & 1050 & 43.1 \\
\hline
\end{tabular}



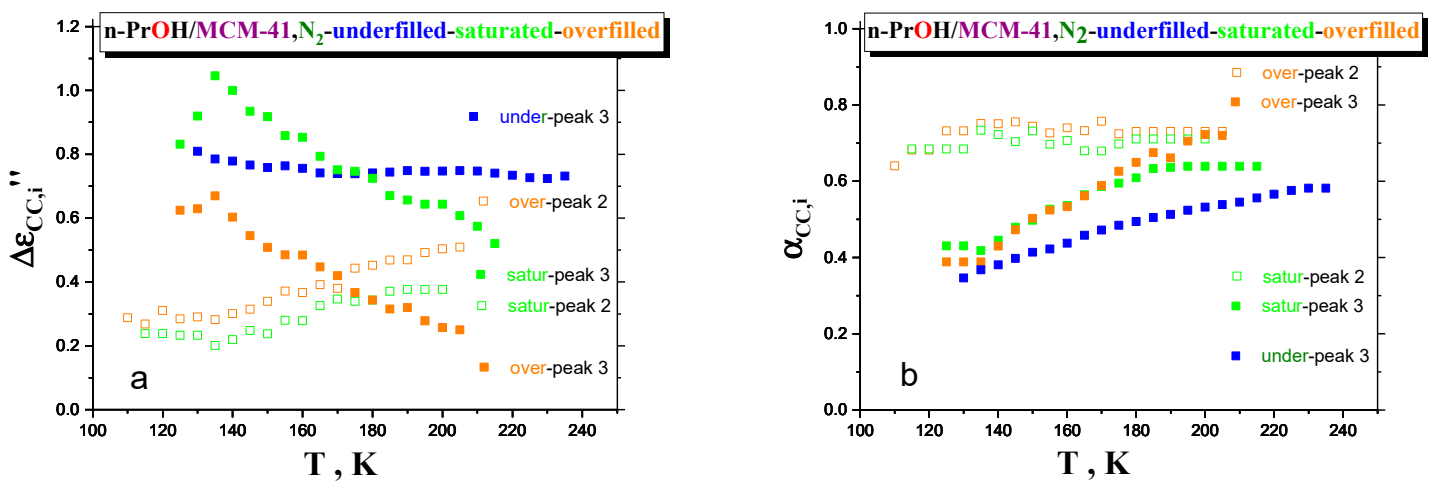

Figure 8. Temperature dependences of the relaxation strength (a) and shape parameter (b) for all the three variously filled confined $n-\mathrm{PrOH} / \mathrm{MCM}-41, \mathrm{~N}_{2}$ systems.

Two groups of the timescales are clearly evident. The lower-frequency peak 3 appears in all the three confined underfilled, saturated and overfilled $n-\mathrm{PrOH} / \mathrm{MCM}-41$ systems, while in the former case, it is slower than in the remaining cases with the rather comparable timescales. On the other hand, the higher-frequency peak 2 is observable only in the saturated and overfilled $n-P r O H / M C M-41$ systems, with its frequency position lower, but quite close to that of the main peak in the bulk n-PrOH medium. Moreover, a slight difference does exist between the two confined cases in the spirit that the overfilled sample lies mostly in between the saturated n-PrOH/MCM-41 system and the bulk $n-\mathrm{PrOH}$.

Further, short-range low- $T$ extrapolations of the corresponding VFTH equations provide the pseudo glass transition temperatures, " $T_{\mathrm{g}}$ ", operationally defined as the temperatures at which the peak maximum relaxation time reaches $100 \mathrm{~s}$. In such a way determined " $T_{\mathrm{g}}$ " values for two basic relaxations in the confined $n-P r O H / M C M-41$ systems are as follows: " $T_{\mathrm{g}}$ " (peak 3) $=116 \pm 1 \mathrm{~K}$ and " $T_{\mathrm{g}}$ " $($ peak 2$)=101.5 \pm 0.5 \mathrm{~K}$. The latter value is comparable with " $T_{\mathrm{g}}$ " (bulk) $=104.5 \mathrm{~K}$, as determined for the main peak in the bulk $n-\mathrm{PrOH}$ medium. Note that, in the case of the bulk $n-\mathrm{PrOH}$, the main peak consists of the dominating, slower Debye process and the smaller and faster primary $\alpha$ relaxation, which correlates with the calorimetric and mechanical data. Consequently, this latter process is related to the true glass transition temperature, $T_{\mathrm{g}}(\mathrm{bulk})=99 \mathrm{~K}$, being lower than the pseudo glass transition temperature, " $T_{\mathrm{g}}$ "(bulk) = $104.5 \mathrm{~K}[39,46-48]$.

Figure $8 \mathrm{a}, \mathrm{b}$ displays two further relaxation parameters, i.e., relaxation strengths, $\Delta \varepsilon_{\mathrm{CC}, \mathrm{i}}$, and shape parameters, $\alpha_{\mathrm{CC}, \mathrm{i}}$, of processes 3 and 2, as a function of temperature. By increasing the temperature, for the underfilled sample, the relaxation strength of process 3 remains quasi-constant. On the other hand, the mutually opposite trends in the relative strengths for processes 3 and 2 in the saturated and overfilled ones are observed. In particular, the corresponding quantities for process 3 decrease, while those for the process 2 increase with elevated temperature. Finally, the shape parameter gradually increases for the underfilled system, indicating the narrowing the relaxation-time distribution. As for the saturated and overfilled samples, a similar effect is found for the lower frequency process 3 with a quasi-saturation at higher-T region for the former, but with continuing narrowing for the later approaching that for the high-frequency process 2 . As for the high-frequency process 2 , for both the samples, the $\alpha_{\mathrm{CC}, \mathrm{i}}$ values are more or less close and quasi-constant with an increasing temperature.

\section{Discussion}

On the basis of these experimental findings, we suggest the existence of one dynamic phase in the underfilled samples, in contrast to the presence of two distinguishable dynamic ones in the saturated and overfilled $n-\mathrm{PrOH} / \mathrm{MCM}-41$ systems almost independently on the preparation atmosphere. These distinct dynamic phases can be ascribed as follows (see also schematic heterogeneous dynamic model of protic polar organic medium in polar inorganic matrix in Figure 9). 
Bulk state:

\section{Confined states:}
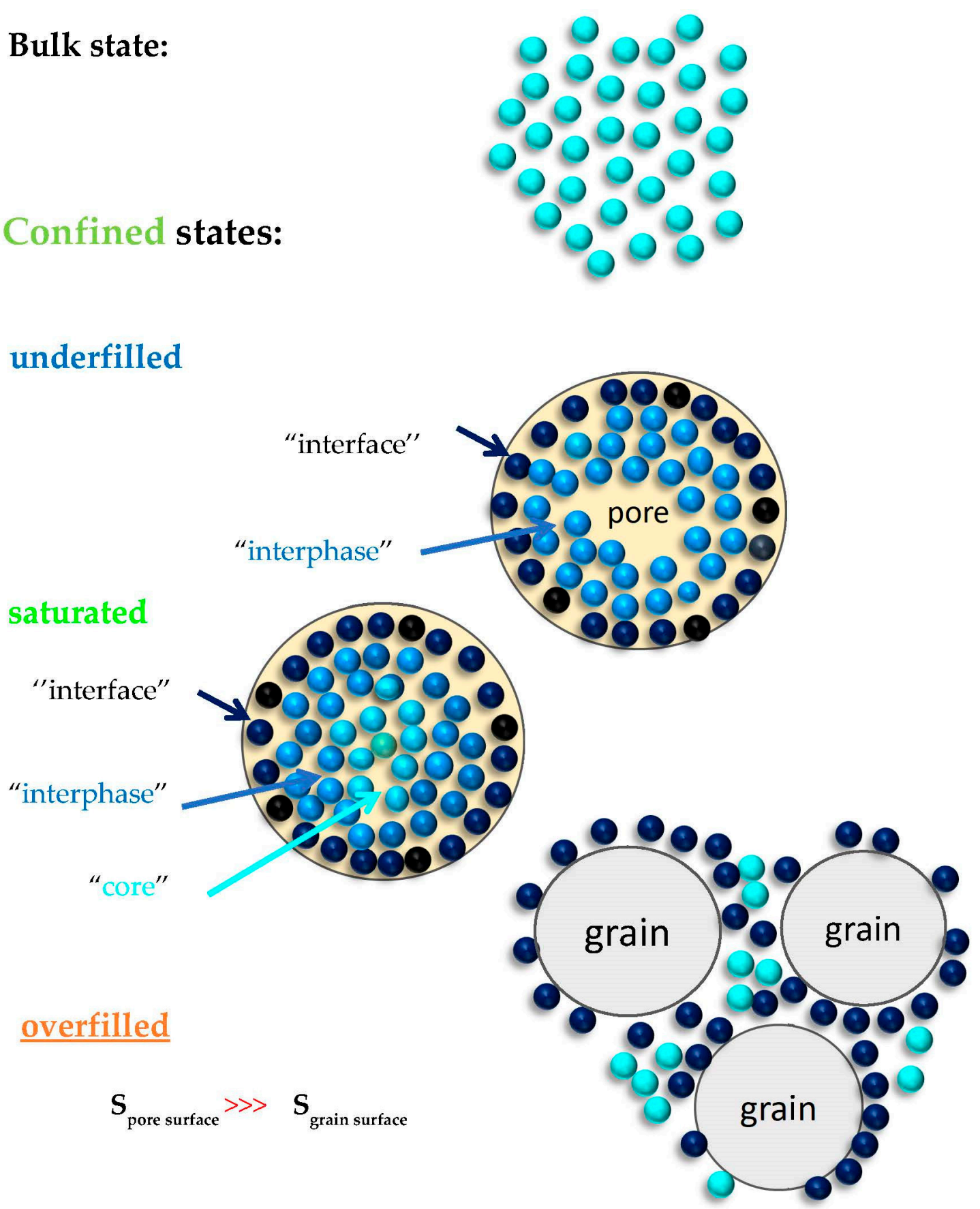

Figure 9. Schematic heterogeneous dynamic model of protic polar organic medium in polar inorganic matrix. Three basic structural-dynamic features in three confined $n-P r O H / M C M-41$ systems are as follows: (i) "interface" formed by the monomolecular layer of the polar molecules of n-PrOH medium, the rest polar $\mathrm{H}_{2} \mathrm{O}$ molecules directly anchored to the polar $\equiv \mathrm{SiOH}$ groups at the pore surface of MCM-41 matrix, as well as by the possible alkoxy-groups; (ii) "interphase", i.e., quasi-ordered layer of the amphiphilic polar molecules of $n$-PrOH medium; and (iii) "core", i.e., the bulk-like polar molecules of n-PrOH medium at the central part of pore of the MCM-41 matrix (see the text). Note that, while in the first two underfilled and saturated cases the pore vs. $n$-PrOH medium particle sizes relationships are depicted more or less realistically from the mutual size viewpoint, in the overfilled one, the mutual relationships between the $n$-PrOH medium molecules and the grain sizes are oversimplified due to the essential difference between their dimensions: $D_{\text {grain }}$ (a few $\left.\mu \mathrm{ms}\right)>>>D_{\mathrm{n}-\mathrm{PrOH}}{ }^{\mathrm{vdW}, \mathrm{eq}}$ (a few nms). 
In the underfilled $n-\mathrm{PrOH} / \mathrm{MCM}-41$ sample, the protic polar $n$ - $\mathrm{PrOH}$ molecules are localized at the polar wall of the pore surface due to their H-bonding interaction with the silanol groups. Moreover, according to the very recent detailed systematic work, a series of the small molecular alkanols ranging from methanol to octanol, also including n-propanol, react with these surface silanol groups of the MCM-41 matrix, even at room temperature, under forming the corresponding polar alkoxy groups [49]. Thus, the true interface appears to contain three components, i.e., the rest adsorbed $\mathrm{H}_{2} \mathrm{O}$ molecules, the intermolecularly $\mathrm{H}$-bonded $n$-PrOH ones and the alkoxy groups to the silica surface. As our filling fraction of 0.24 exceeds the monomolecular layer case, i.e., true interface sometimes called the contact layer, also the adjacent layers of the $n-\mathrm{PrOH}$ molecules named interphase contribute to the dielectric response. This formation of one or a few layers adjacent to the contact layer is supported by the amphiphilic character of the $n-\mathrm{PrOH}$ molecules, where the polar hydroxyl group $-\mathrm{OH}$ of the $n$ - $\mathrm{PrOH}$ medium are attached directly via $\mathrm{H}$-bonding to the polar silanol groups and even covalently via alkoxy groups $\equiv \mathrm{SiO}\left(\mathrm{CH}_{2}\right)_{2} \mathrm{CH}_{3}$. On the other side, the apolar propyl- $\mathrm{CH}_{2} \mathrm{CH}_{2} \mathrm{CH}_{3}$ parts of the $n$-PrOH molecules are directed into the pore, where it can preferentially interact with the same propyl groups from the first adjacent layer. This probably gave rise to the more denser interphase region with the higher orientational order which can be reduced in direction toward the central part of the pore of the $M C M-41$ matrix. In addition to the overwhelming amount of $n-\mathrm{PrOH}$ medium, the inevitable remaining $\mathrm{H}_{2} \mathrm{O}$ molecules from the used drying procedure under $\mathrm{N}_{2}$ atmosphere, as well as the potential alkoxy groups, also contribute, to a minor extent, to the total spectrum, as evidenced from Figures 2 and 5.

Next, for the almost saturated $n-\mathrm{PrOH} / \mathrm{MCM}-41$ case, besides this combined interface and interphase slower regions, the additional faster dynamic component in the BDS spectra is attributed to the more distant $n-\mathrm{PrOH}$ molecules from the pore surface which are localized in the central part, i.e., the so-called "core" region of the pore of the MCM-41 matrix. As it is seen from Figure 7, the $n$-PrOH molecules in this central "core" region exhibit a somewhat slower dynamics compared to that in the bulk n-PrOH medium, so that they exhibit the bulk-like behavior.

Finally, in the overfilled $n-\mathrm{PrOH} / \mathrm{MCM}-41$ system with $\mathrm{f}=0.46$, an exceeding part of the $n-\mathrm{PrOH}$ medium over the saturated filling fraction 0.39 must be situated outside of the MCM-41 grains. Consequently, while the dynamics of the $n-\mathrm{PrOH}$ stemming from the confined part of the $n-\mathrm{PrOH}$ in the intrapores is rather similar to that from the saturated case, the dynamics of the exceeding part of the $n-P r O H$ filler is a bit faster compared to the fully filled case, but still a bit slower than in the bulk $n$-PrOH medium. This is also due to some contribution from the $n-\mathrm{PrOH}$ molecules in the free space between the MCM-41 grains which are partially bonded to the outer surface of the MCM-41 grains. As the outer grain surface in the MCM-41 matrix is essentially smaller than the inner pore surface within the pores of the MCM- 41 grains, the bounded $n-P r O H$ in this outer interface (and eventually some interphase) will contribute in significantly smaller extent, so that the higher relative intensity of peak 2 compared to peak 3 stems from the $n$ - $\mathrm{PrOH}$ medium in the intergrain (interpore) spaces with the bulk-like behavior (Figures 5 and 8).

The fact that process 2 is narrow and its shape does not change appreciably with temperature supports the interpretation of this process as originated by bulk-like $n$ - $\mathrm{PrOH}$ molecules. Concerning the relative strength of processes 2 and 3 and their temperature dependence, it is consistent with the expectation that the number of molecules behaving as bulk-like increases with temperature due to an increase of mobility and a decrease of the size or number of cooperating molecules. Consistently, the strength of process 3 in the underfilled sample remains more or less constant, as in this sample, molecules just belong to the first monolayer interface and to interphase, and their number is too low to switch to a bulk-like behavior as temperature increases. In line with these observations, the $T$-dependence of the characteristic times of process 2 is more "fragile", and process 3 becomes "stronger" the lower the $n-\mathrm{PrOH}$ content.

In connection with the aforementioned findings and their interpretation in terms of distinct dynamic phases, it is of interest to see how the BDS spectra of the saturated $n-P r O H / M C M-41, N_{2}$ sample evolves during simple gradual thermal treatment at $300 \mathrm{~K}$, followed by that at $310 \mathrm{~K}$, as performed 
directly in the BDS cell, i.e., during "drying", the confined $n-P r O H / M C M-41, N_{2}$ system due to the release of the $n-\mathrm{PrOH}$ medium. Figure 10a shows the spectral changes for the saturated sample first cooled and measured at the selected temperature of $175 \mathrm{~K}$ (scan 1) and after two heatings that followed, for seven minutes, at $300 \mathrm{~K}$. While peak 3 remains the same during all the heating cycles (scans 2 and 3), peak 2 at almost the same position decreased due to evaporation of the $n$-PrOH medium from the central region of the pore of the MCM-41 matrix, where the $n-\mathrm{PrOH}$ molecules interact mutually by the weaker intermolecular forces than the ones bounded directly to and being more adjacent to the polar surface wall of the pores of the MCM-41 matrix. Comparison with the first scan of the overfilled $n-\mathrm{PrOH} / \mathrm{MCM}-41, \mathrm{~N}_{2}$ sample (Figure 7) shows that the position of peak 3 is the same for both samples. In contrast, peak 2 is more intense, indicating somewhat looser dynamics for this process in the overfilled sample compared to the similar peak 2 in the saturated sample. This would be evidence of the excess $n$-PrOH medium localized outside the pores of the MCM- 41 matrix. Next, the temperature of this partially dried sample was increased toward $310 \mathrm{~K}$, and heating and cooling cycles were repeated 17 times, with subsequent detection of the spectra at $175 \mathrm{~K}$ (see Figure 10b). As it can be seen, peak 2 is gradually fully eliminated, and peak 3 is also gradually reduced, with a slight shift toward the lower frequencies. Thus, all these observations appear to be consistent with the picture of two distinct dynamic phases and support the proposed schematic model in Figure 9.
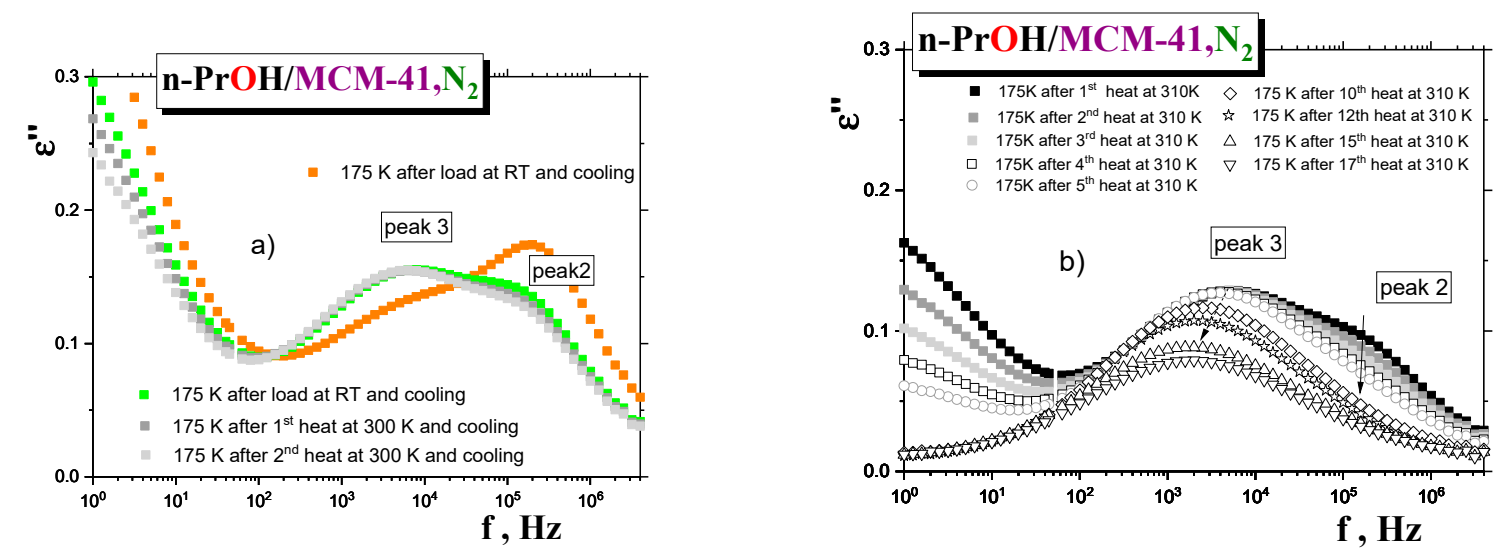

Figure 10. Spectral evolution of the originally saturated $n-\mathrm{PrOH} / \mathrm{MCM}-41, \mathrm{~N}_{2}$ system, after two heating-cooling cycles at $300 \mathrm{~K}$ (a) and after following seventeen-fold heating-cooling ones at $310 \mathrm{~K}$ (b). BDS spectrum for the overfilled sample is added for comparison.

\section{Conclusions}

We presented a detailed investigation of the relaxation dynamics in the representative of short-chain n-alkanols, namely n-propanol confined in the regular MCM-41 matrix as a function of a series of external parameters by low-frequency dielectric spectroscopy. These external parameters concerned the following three issues: (i) conditioning the empty MCM-41 matrix and its subsequent filling into the capacitor under various atmospheres, i.e., air or $\mathrm{N}_{2}$; (ii) conditioning the empty $M C M-41$ matrix and subsequent filling the $n-\mathrm{PrOH}$ medium into the capacitor under various atmospheres; and finally (iii) variation of the filling factor for the most optimally treated MCM-41 matrix. In the first case, relatively large sensitivity of the BDS response of the empty MCM- 41 to its various atmospheres, especially at the capacitor filling, was found. In the second one, in spite of this, the dynamics are not very essentially affected by the used environment at the pores, as well as at the capacitor filling. Finally, the filling factor has a paramount impact on the spectral form of the BDS response, indicating the spatial heterogeneity of the dynamics of the confined $n-\mathrm{PrOH}$ in $\mathrm{MCM}-41$ matrix due to the presence of the two distinct dynamic phases.

Author Contributions: J.B. proposed the research topic, participated in BDS measurements, evaluated and analyzed the BDS spectra and formulated the manuscript; S.A.-I. and H.Šs. performed detailed BDS measurement 
and evaluations; A.K. performed M-IR measurements; and A.A. participated at BDS experiments. All authors have read and agreed to the published version of the manuscript.

Funding: This research was funded by the EUSMI/Horizon 2020 grants: E181200215 and E 180300076 and E180300077 and by the Slovak Research and Development Agency (SRDA) under the contract No. APVV-16-0369. And J.B. was funded by the VEGA Agency, Slovakia with Grant No. 2/0030/16.

Conflicts of Interest: The authors declare no conflict of interests.

\section{References}

1. Thompson, W.H. Perspective: Dynamics of confined liquids. J. Chem. Phys. 2018, 149, 170901. [CrossRef] [PubMed]

2. Huber, P. Soft matter in hard confinement: Phase transition thermodynamics, structure, texture, diffusion and flow in nanoporous media. J. Phys. Cond. Matter 2015, 27, 103102. [CrossRef] [PubMed]

3. Alba-Simionesco, C.; Coasne, B.; Dosseh, G.; Dudziak, G.; Gubbins, K.E.; Radhakrishnan, R.; Sliwinska-Bartkowiak, M. Effects of confinement on freezing and melting. J. Phys. Cond. Matter 2006, 18, R15-R68. [CrossRef] [PubMed]

4. Alcoutlabi, M.; McKenna, G.B. Effects of confinement on material behavior at the nanometre size scale. J. Phys. Cond. Matter 2005, 17, R461-R524. [CrossRef]

5. Kremer, F. Dynamics in Geometrical Confinement; Springer: Heidelbeg, Germany, 2014.

6. Richert, R. Dynamics of nanoconfined supercooled liquids. Ann. Rev. Phys. Chem. 2011, 62, 65-84. [CrossRef]

7. Kremer, F.; Schönhals, A. Broadband Dielectric Spectroscopy; Springer: Berlin, Germany, 2003.

8. Schönhals, A.; Zorn, R.; Frick, B. Inelastic neutron scattering as a tool to investigate nanoconfined polymer systems. Polymer 2016, 105, 393-406. [CrossRef]

9. Kruteva, M.; Wischnevski, A.; Richter, D. Polymer dynamics in nanoconfinement: Interfaces and interphases. Eur. Phys. J. Conf. 2015, 83, 02009. [CrossRef]

10. Kresge, C.T.; Roth, W.J. The discovery of mesoporous molecular sieves from the twenty year perspective. Chem. Soc. Rev. 2013, 42, 3663-3670. [CrossRef]

11. Beck, J.S.; Vartuli, J.C.; Roth, W.J.; Leonowicz, M.E.; Schmidt, K.D.; Chu, C.T.W.; Olson, D.H.; Sheppard, E.W.; McCullen, S.B.; Higgins, J.B.; et al. A New Family of Mesoporous Molecular Sieves Prepared with Liquid Crystal Templates. J. Am. Chem. Soc. 1992, 114, 10834-10843. [CrossRef]

12. Kresge, C.T.; Leonowicz, M.E.; Vartuli, J.C.; Roth, W.J.; Beck, J.S. Ordered Mesoporous Molecular Sieves Synthetized by Liquid-Crystal Template Mechanism. Nature 1992, 359, 710-712. [CrossRef]

13. Zhao, D.; Huo, O.; Feng, J.; Chmelka, B.F.; Stucky, G.D. Nonionic Triblock and Star Diblock Copolymer and Oligomeric Surfactant Syntheses of Highly Ordered, Hydrothermally Stable, Mesoporous Silica Structures. J. Amer. Chem. Soc. 1998, 120, 6024-6036. [CrossRef]

14. Zhao, D.; Feng, J.; Huo, Q.; Melosh, N.; Fredrickson, G.H.; Chmelka, B.F.; Stucky, G.D. Triblock Copolymer Syntheses of Meso-porous Silica with Periodic 50 to 300 Angstrom Pores. Science 1998, 279, 548-552. [CrossRef] [PubMed]

15. Vansant, E.F.; Van der Woort, P.; Vrancken, K.C. Characterization and Chemical Modification of the Silica Surface. Stud. Surf. Sci. Cat. 1995, 93, 3-556.

16. Iler, R.K. The Chemistry of Silica; Chpt. 6; A Wiley Interscince Publication Press: New York, NY, USA, 1979.

17. Zhao, X.S.; Lu, G.Q.; Whittaker, A.K.; Millar, G.J.; Zhu, H.Y. Comprehensive Study of Surface Chemistry of MCM-41 Using ${ }^{29}$ Si CP/MAS NMR, FTIR, Pyridine-TPD, and TGA. J. Phys. Chem. B 1997, 101, 6525-6531. [CrossRef]

18. Chen, J.; Li, Q.; Xu, R.; Xiao, F. Distinguining the Silanol Groups in the Mesoporous Molecular Sieve MCM-41. Angew. Chem. Int. Ed. Engl. 1995, 34, 2694-2696. [CrossRef]

19. Ryabov, Ya.; Gutina, A.; Arkhipov, V.; Feldman, Yu. Dielectric relaxation of Water Adsorbed in Porous Glass. J. Phys. Chem. B 2001, 105, 1845-1850. [CrossRef]

20. Sjörström, J.; Swenson, J.; Bergman, R.; Kittaka, S. Investigating hydration dependence of dynamics of confined water: Monolayer, hydration water and Maxwell-Wagner processes. J. Chem. Phys. 2008, 128, 154503. [CrossRef] 
21. Banys, J.; Kinka, M.; Macutkevic, J.; Völkel, G.; Böhlmann, W.; Umaheswari, V.; Hartman, M.; Pöppl, A. Broadband dielectric spectroscopy of water confined in MCM-41 molecular sieve materials. J. Phys. Cond. Matter 2005, 17, 2843-2857. [CrossRef]

22. Spanoudaki, A.; Albela, B.; Bonneviot, L.; Peyrard, M. The dynamics of water in nanoporous silica studied by dielectric spectroscopy. Eur. Phys. J. E 2005, 17, 21-27. [CrossRef]

23. Cerveny, S.; Schwartz, G.A.; Otegui, J.; Colmenero, J.; Loichen, J.; Westermann, J.S. Dielectric Study of Hydration Water in Silica Nanoparticles. J. Phys. Chem. C 2012, 116, 24340-24349. [CrossRef]

24. Kityk, A.V.; Huber, P.; Pelster, R.; Knorr, K. Spatial Variation of Molecular Dynamics in the Nanoconfined Glass-Former Methanol. J. Phys. Chem. C 2014, 118, 12548-12554. [CrossRef]

25. Pissis, P.; Daoukaki-Diamanti, D.; Apekis, L.; Christodoulides, C. The glass transition on confined liquids. J. Phys. Cond. Matter 1994, 6, L325-L328. [CrossRef]

26. Gorbatschow, W.; Arndt, M.; Stannarius, R.; Kremer, F. Dynamics of H-bonded liquids confined to nanopores. Europhys. Lett. 1996, 35, 719-724. [CrossRef]

27. Huwe, A.; Arndt, M.; Kremer, F.; Haggenmueller, C.; Behrens, P. Dielectric investigations of the molecular dynamics of propanediol in mesoporous silica materials. J. Chem. Phys. 1997, 107, 9699-9701. [CrossRef]

28. Pelster, R. Dielectric spectroscopy of polar compounds. Phys. Rev. B 1999, 59, 9214-9228. [CrossRef]

29. Kremer, F.; Huwe, A.; Arndt, M.; Behrens, P.; Schwieger, W. How many molecules form a liquid? J. Phys. Cond. Matter 1999, 11, A175-A188. [CrossRef]

30. Fischer, J.K.H.; Sippel, P.; Denysenko, D.; Lunkenheimer, P.; Volkmer, D.; Loidl, A. Metal-organic frameworks as host materials of confined supercooled liquids. J. Chem. Phys. 2015, 143, 154505. [CrossRef]

31. Janssen, H.; Swensson, J. The slow dielectric Debye relaxation of mono alcohols in confined geometries. J. Chem. Phys. 2011, 134, 104504. [CrossRef]

32. Gainaru, C.; Schildmann, S.; Böhmer, R. Surface and confinement effects on the dielectric relaxation of a Monohydroxy alcohol. J. Chem. Phys. 2011, 135, 174510. [CrossRef]

33. Takahara, S.; Kittaka, S.; Mori, T.; Kuroda, Y.; Takamuku, T.; Yamaguchi, T. Neutron Scattering and Dielectric Studies on Dynamics of Methanol and Ethanol Confined in MCM-41. J. Phys. Chem. C 2008, 112, 14385-14393. [CrossRef]

34. Böhmer, R.; Gainaru, C.; Richert, R. Structure and dynamics of monohydroxy alcohols—Milestones towards their microscopic understanding, 100 years after Debye. Phys. Rep. 2014, 545, 125-195. [CrossRef]

35. Sillrén, P.; Swenson, J.; Mattsson, J.; Bowron, D.; Matic, A. The temperature dependent structure of liquid 1-propanol as studied by neutron diffraction and EPSR simulations. J. Chem. Phys. 2013, 138, 214501. [CrossRef] [PubMed]

36. Sillrén, P.; Bielecki, J.; Mattsson, J.; Börjesson, L.; Matic, A. A statistical model of hydrogen bond networks in liquid alcohols. J. Chem. Phys. 2012, 136, 094514. [CrossRef] [PubMed]

37. Vrhovšek, A.; Gereben, O.; Jamnik, A.; Pusztai, L. Hydrogen Bonding and Molecular Aggregates in Liquid Methanol, Ethanol and 1-Propanol. J. Phys. Chem. B 2011, 115, 13473-13488. [CrossRef]

38. Vrhovšek, A.; Gereben, O.; Pothoczki, S.; Tomšič, M.; Jamnik, A.; Kohara, S.; Pusztai, L. An approach towards understanding the structure of complex molecular systems: The case of lower aliphatic alcohols. J. Phys. Cond. Matter 2010, 22, 404214. [CrossRef]

39. Hansen, C.; Stickel, F.; Berger, T.; Richert, R.; Fischer, E.W. Dynamics of glass-forming liquids. III. Comparing the dielectric $\alpha$-and $\beta$-relaxation of 1-propanol and o-terphenyl. J. Chem. Phys. 1997, 107, 1086-1093. [CrossRef]

40. Kudlik, A.; Tschirwitz, C.; Benkhof, S.; Blochowicz, T.; Rössler, E. Slow secondary relaxation process in supercooled liquids. Europhys. Lett. 1997, 40, 649-654. [CrossRef]

41. Sillrén, P.; Matic, A.; Karlsson, M.; Koza, M.; Maccarini, M.; Fouquet, P.; Götz, M.; Bauer, T.; Gulich, R.; Lunkenheimer, P.; et al. Liquid 1-propanol studied by neutron scattering, near-infrared and dielectric spectroscopy. J. Chem. Phys. 2014, 140, 124501. [CrossRef]

42. Cabrillo, C.; Barroso-Bujans, F.; Fernandez-Perea, R.; Fernandez-Alonso, F.; Bowron, D.; Bermejo, F.J. Adsorbate-induced bilayer orderning of 1-propanol-graphiteoxide intercalates. Carbon 2016, 100, 546-555. [CrossRef]

43. Bartoš, J.; Švajdlenková, H.; Šauša, O.; Lukešová, M.; Ehlers, D.; Michl, M.; Lunkenheimer, P.; Loidl, A. Molecular probe dynamics and free volume in organic glass-formers and their relationships to structural relaxation: 1-propanol. J. Phys. Cond. Matter 2016, 28, 015101. [CrossRef] 
44. Bartoš, J.; Lukešová, M.; Švajdlenková, H.; Šauša, O. Bulk and confined non-polar and polar chain-like organics by external probing ESR technique. AIP Conf. Proceed. 2018, 1981, 020081.

45. Bartoš, J.; Švajdlenková, H.; Šauša, O. Molecular probe mobility and free volume heterogeneities in n-propanol confined in regular MCM-41 matrix by ESR and PALS. RSC Advances 2020, 10, 2283-2294. [CrossRef]

46. Murthy, S.N.; Tyagi, M. Experimental study of the high frequency relaxation process in monohydroxy alcohols. J. Chem. Phys. 2002, 117, 3837-3847. [CrossRef]

47. Wang, L.-M.; Richert, R. Dynamics of glass-forming liquids. IX. Structural versus dielectric relaxation in monohydroxy alcohols. J. Chem. Phys. 2004, 121, 11170-11176. [CrossRef] [PubMed]

48. Wang, L.-M.; Tian, Y.; Liu, R.; Richert, R. Calorimetric versus kinetic glass transition in viscous mono-hydroxy alcohols. J. Chem. Phys. 2008, 128, 084503. [CrossRef] [PubMed]

49. Björklund, S.; Kocherbitov, V. Alcohols react with MCM-41 at room temperature and chemically modify mesoporous silica. Sci. Rep. 2017, 7, 9960. [CrossRef]

(C) 2020 by the authors. Licensee MDPI, Basel, Switzerland. This article is an open access article distributed under the terms and conditions of the Creative Commons Attribution (CC BY) license (http://creativecommons.org/licenses/by/4.0/). 